\title{
ARQUITECTURA E INVESTIGACIÓN CON FÁBRICA ARMADA
}

\section{(ARCHITECTURE AND RESEARCH WITH REINFORCED MASONRY)}

Josep M. Adell Argilés, Dr. Arquitecto

Profesor Titular del Departamento de Construcción y Tecnología Arquitectónicas

Escuela T.S. de Arquitectura-Universidad Politécnica de Madrid.

ESPAÑA

Fecha de recepción: 4-IX-92

$631-9$

\section{RESUMEN}

Las primeras aplicaciones de la fábrica armada con voluntad arquitectónica, son expuestas por el Arquitecto autor de las obras.

Las originales realizaciones mostradas, son reflejo del entendimiento de la fábrica armada, como un nuevo material compuesto arquitectónico.

La investigación llevada a cabo, de carácter técnico-formal, desarrolla planteamientos teóricos y prácticos, en busca de mejorar el funcionamiento de las fábricas en la Arquitectura.

\section{SUMMARY}

The Architect, author of the works, offers the first applications of the reinforced masonry with architectural will.

The original realizations shown here are reflections of the understanding of the reinforced masonry as a new composite architectonic material.

The technical-formal research which has been carried out develops the theoretician and practical ideas searching for better functioning of masonries in Architecture.
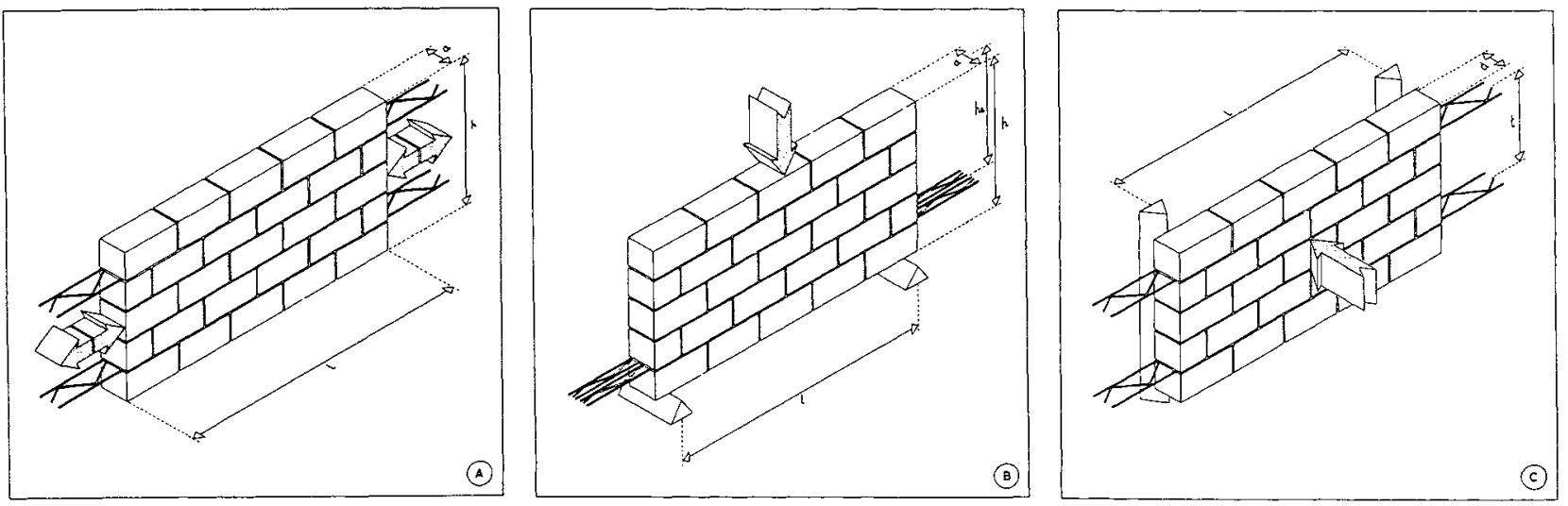

Fig. 1.-Fábrica sometida a: A) Deformaciones impuestas. B) Flexión Vertical. C) Flexión horizontal. 


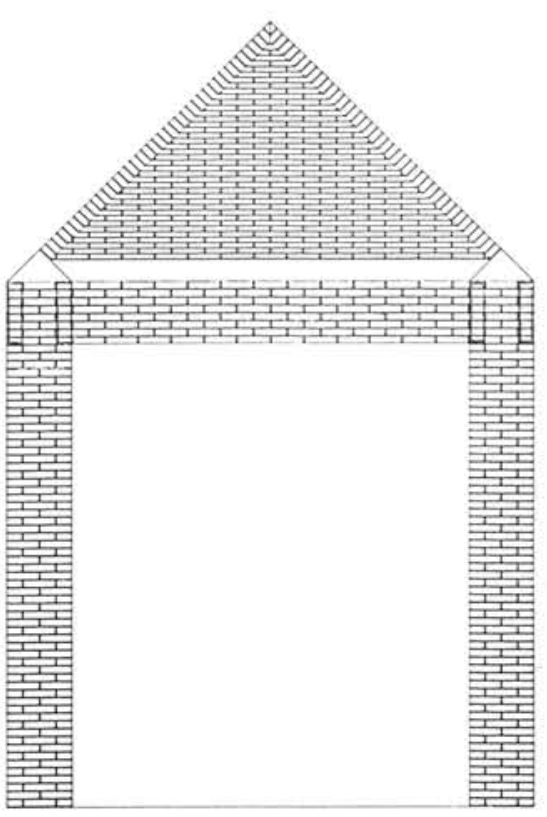

Sección

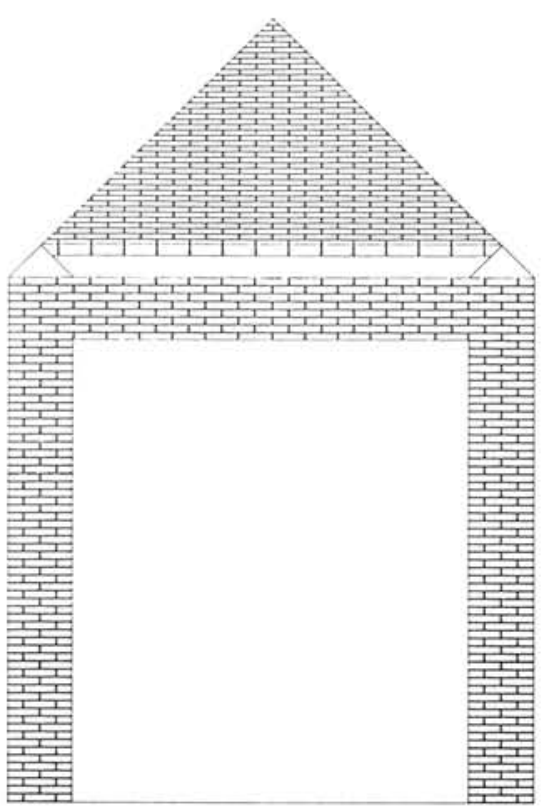

Alzado

VERSIÓN 1
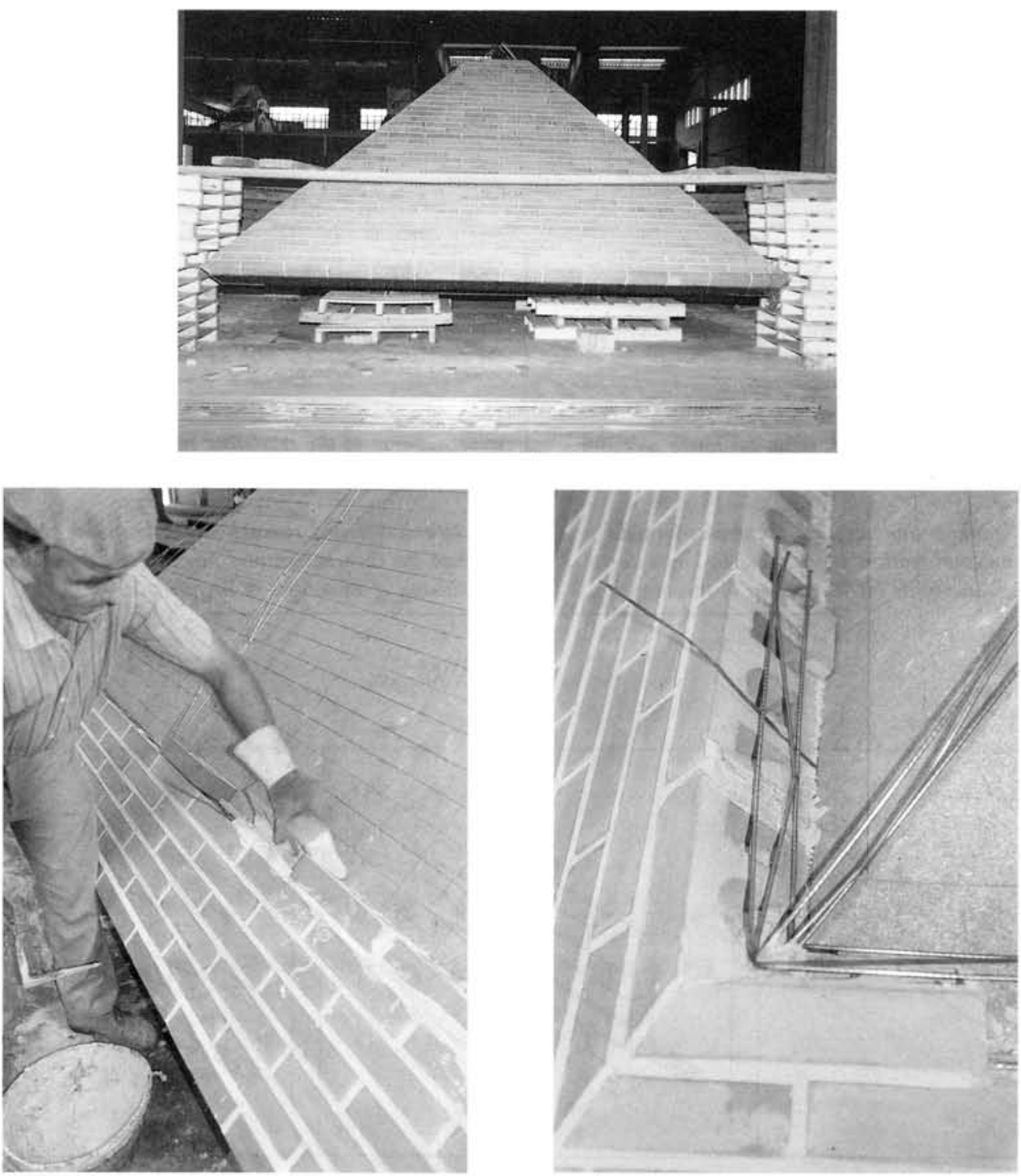

Fig. 2.-Tetrapilono Versión "I". Cubierta con hiladas horizontales. Armaduras Murfor dispuestas en los tendeles.

(c) Consejo Superior de Investigaciones Científicas Licencia Creative Commons 3.0 España (by-nc) 


\section{VERSIÓN 2}
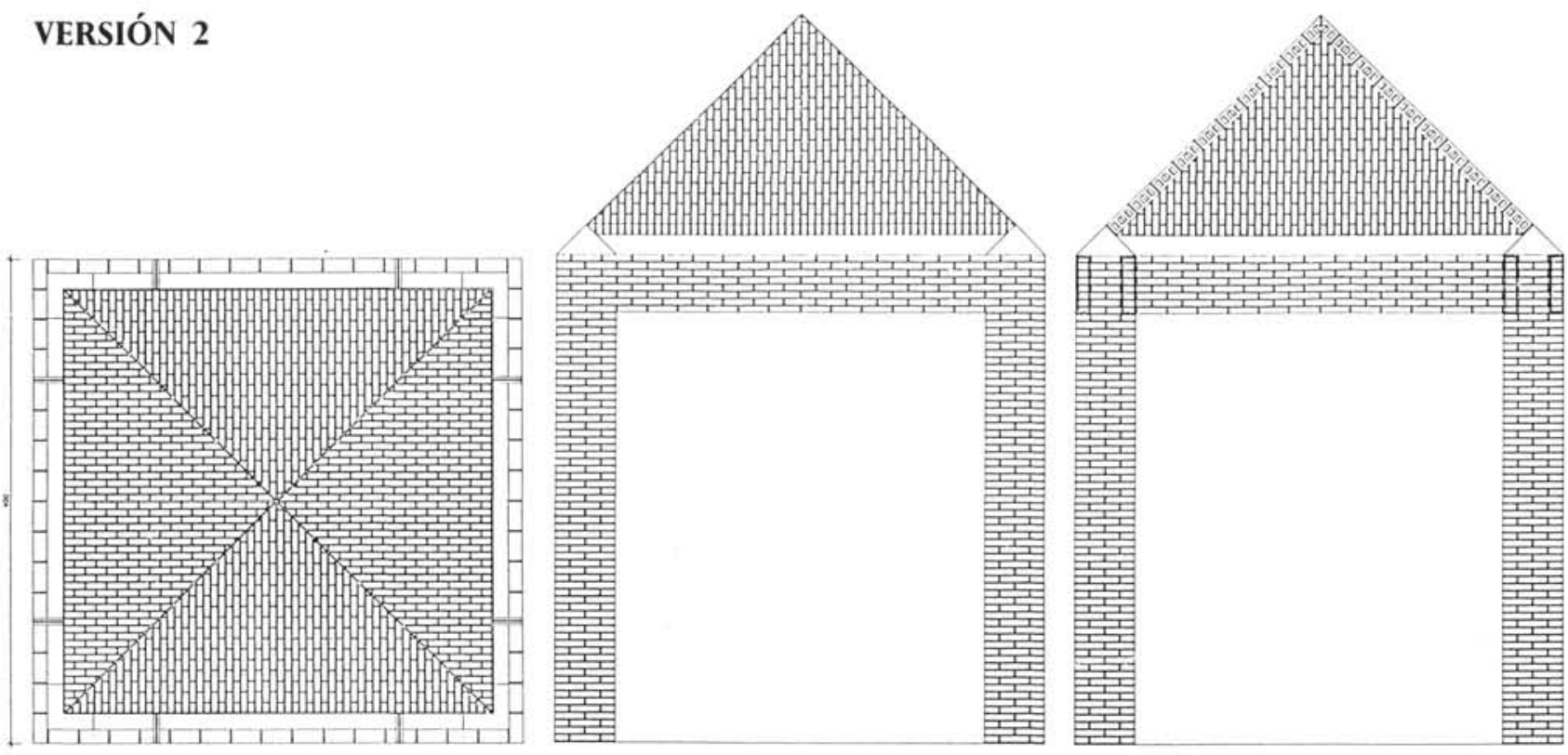

Planta

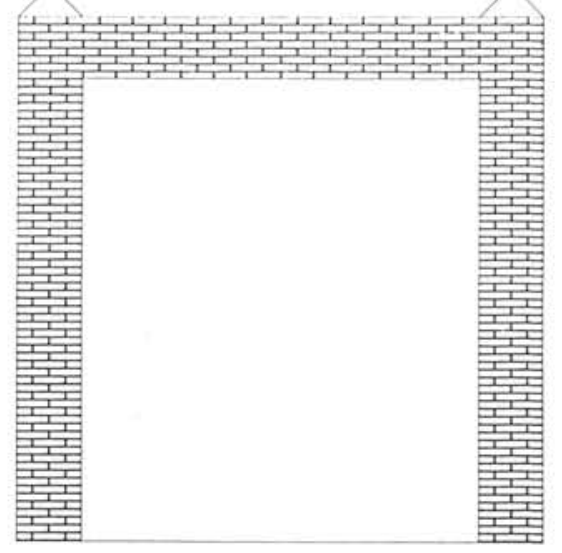

Alzado

Sección
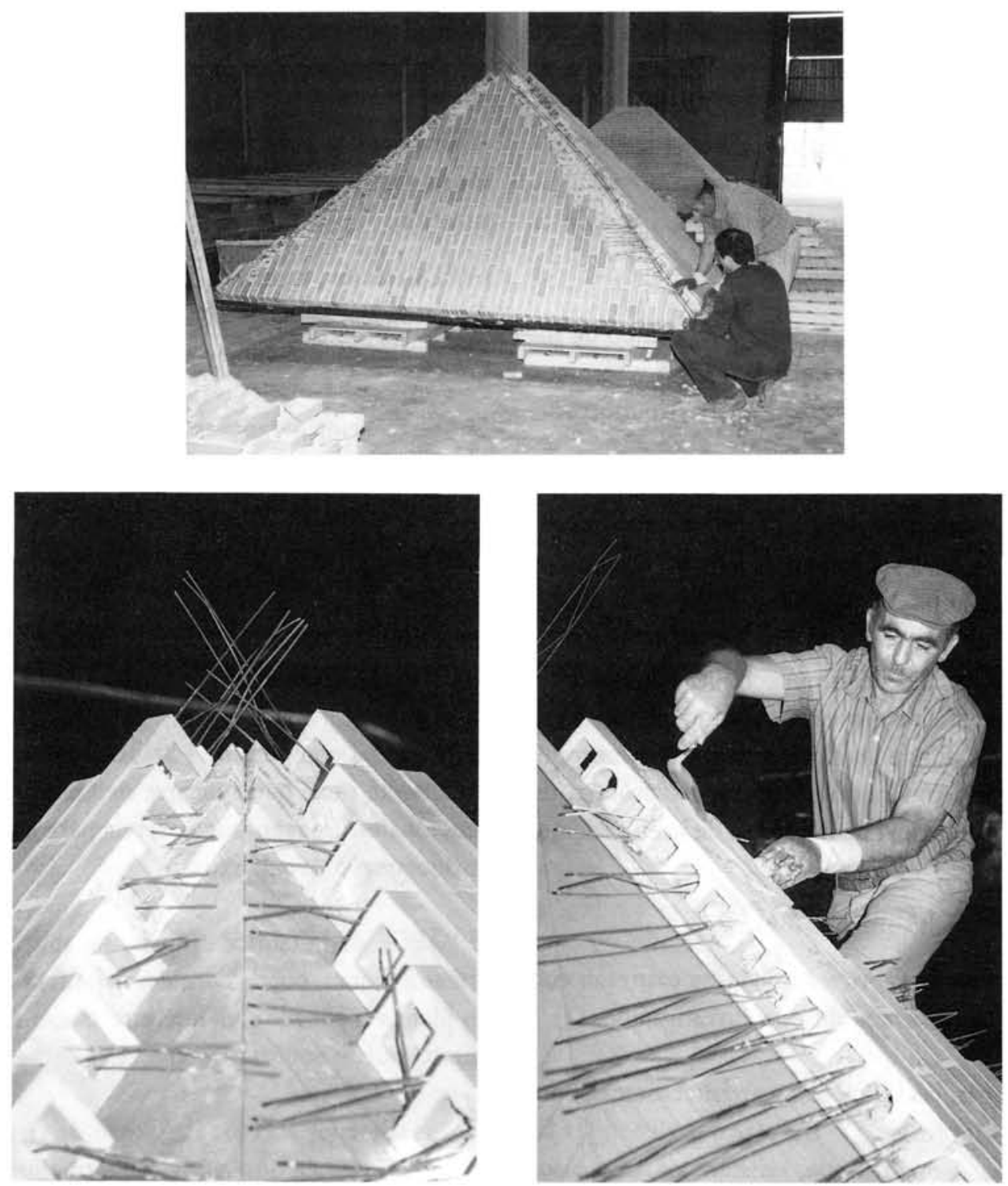

Fig. 2.-Tetrapilono Versión "2". Cubierta con hiladas verticales. Armaduras Murfor a través de los huecos del ladrillo Palau.

(c) Consejo Superior de Investigaciones Científicas Licencia Creative Commons 3.0 España (by-nc) 


\section{INTRODUCCIÓN}

Para poder plantear una investigación nueva en el campo de la Arquitectura, considerando la fábrica armada, es necesario conocer el nuevo material del que estamos hablando.

La fábrica como tal, puede tener distintas cualidades, como corresponde a la diversidad de piezas de albañilería y morteros que se hayan podido utilizar para su construcción.

El acero añade, a las cualidades anteriores, la capacidad de soportar tracciones. Con ello se evita la problemática que genera la rigidez propia de los materiales de albañilería, dotando al compuesto, fábrica armada, de cierta ductilidad.

El uso del ladrillo, de pequeñas dimensiones, aumenta las posibilidades de disponer el armado en la fábrica, al ofrecer ésta mayor densidad de tendeles. Además, su buena resistencia a compresión permite obtener mayor rendimiento de la incorporación del acero. Sin embargo, son notorias las ventajas que se derivan del uso de la fábrica armada con otros materiales.

Con la fábrica armada se abre un amplio campo de investigación, que permite potenciar los aspectos técnicos y formales del uso de las fábricas en la Arquitectura.

La investigación que se presenta surgió de considerar armar la fábrica, posteriormente a estar realizadas las estructuras de los edificios, limitándose pues a cerramiento, particiones, remates...

Considerar las posibilidades arquitectónicas de la fábrica armada, desde la fase de proyecto, permitirá planteamientos más globales, donde las fábricas asuman compromisos estructurales, con notable ahorro del proceso de ejecución, y en beneficio de la calidad de la edificación.

\section{EL “ABC" DE LA FÁBRICA ARMADA}

En Razón y Ser de la Fábrica Armada, se expresan con amplitud los fundamentos de esta investigación. (1)

Antes de entrar en las aplicaciones arquitectónicas, conviene recordar las formas de trabajar que tienen las fábricas armadas. Simplificando, existen los tres casos siguientes (Fig. 1):
(A) Aumento de separación de juntas de dilatación

Armando regularmente los tendeles de la fábrica, se ejerce un control sobre sus movimientos longitudinales, tanto mayor cuanto más próximos se sitúen los têndeles armados.

\section{(B) Flexión vertical}

Colocando localizadamente armaduras en los tendeles inferiores de la fábrica, podrá soportar flexiones en su plano y salvar una distancia entre apoyos con su peso propio, e inclusive sobrecargas, en función del canto del muro, material utilizado y cuantía del armado dispuesto.

\section{(C) Flexión horizontal}

Armando regularmente los tendeles de una fábrica, entre apoyos ortogonales a ellos, podrá soportar flexiones perpendiculares a su plano, debido a cargas que incidan sobre el paramento, en función del grueso del muro, material utilizado y separación de tendeles armados.

Los casos expuestos permiten solucionar, con fábrica armada, problemas típicos de la albañilería, evitando la fisuración:

(A) Dilatación, contracción, retracción.

(B) Dinteles, tabiques con fallo del apoyo.

(C) Acción del viento, empuje del terreno.

Estos tres ejemplos, analizados por separado, pueden darse conjuntamente en la edificación, constituyendo el "ABC" de la "fábrica armada", entendida como un "material compuesto".

\section{INVESTIGACIÓN ARQUITECTÓNICA TÉCNICO-FORMAL}

El "material compuesto" - "fábrica armada", no necesariamente tiene que aplicarse siempre para casos convencionales. Es más, puede servir para experimentar y enriquecer la Arquitectura.

El " $A B C$ " de la fábrica armada, de aplicación para fábricas a plomo, puede considerarse fuera de la vertical, en planos inclinados, ya que este nuevo material compuesto puede soportar flexiones.

Para resaltar los accesos al edificio de viviendas en "El Espinillo", se han diseñado dos "tetrapilonos" en ladrillo, con ligeras variantes entre ellos (Figs. 2). 


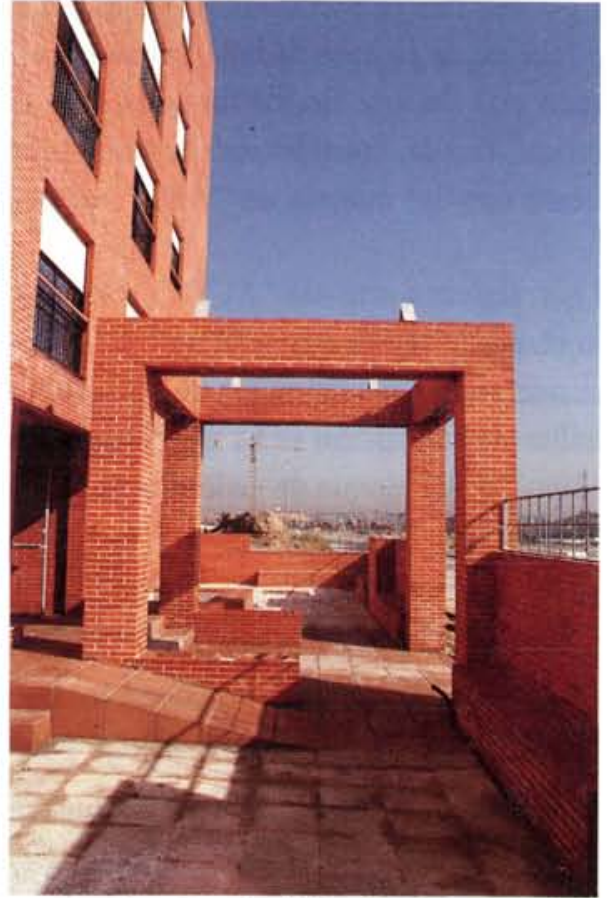

Fig. 3a.-Dinteles dobles de fábrica armada coronando el tetrapilono cúbico.

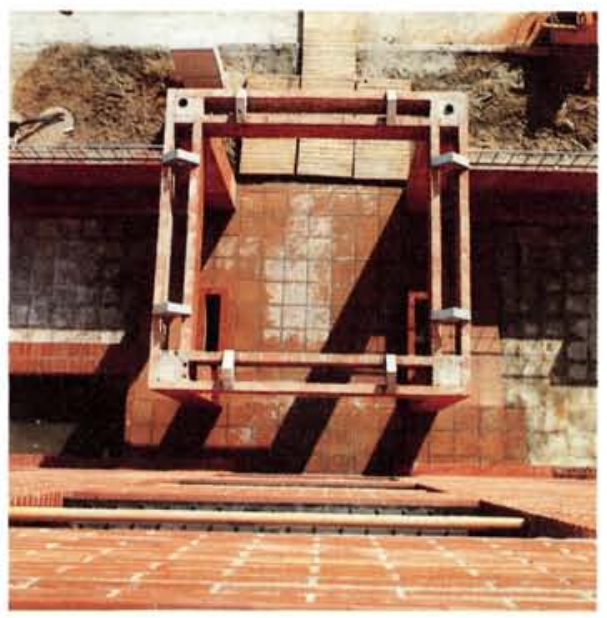

Fig. 4a.-Vista en Planta de los dinteles dobles de apoyo de las cubiertas de los tetrapilonos.

Se trata de dos cubos de $4 \mathrm{~m}$ de lado, definidos por sus aristas de fábrica de $50 \mathrm{~cm}$ de ancho. La cubierta de planos a $45^{\circ}$ está resuelta con fábrica armada de $1 / 2^{\prime}$ de espesor, quedando vista tanto por arriba como por debajo.

La cubierta carga sobre las aristas perimetrales del cubo, constituidas por dobles dinteles de $3 \mathrm{~m}$ de luz, $50 \mathrm{~cm}$ de canto y $11,5 \mathrm{~cm}$ de ancho. En sus primeras y últimas hiladas se han utilizado ladrillos macizos de plano.

Para aumentar el brazo mecánico efectivo del dintel, sin aumentar su canto, se han dispuesto dos armaduras Mur-

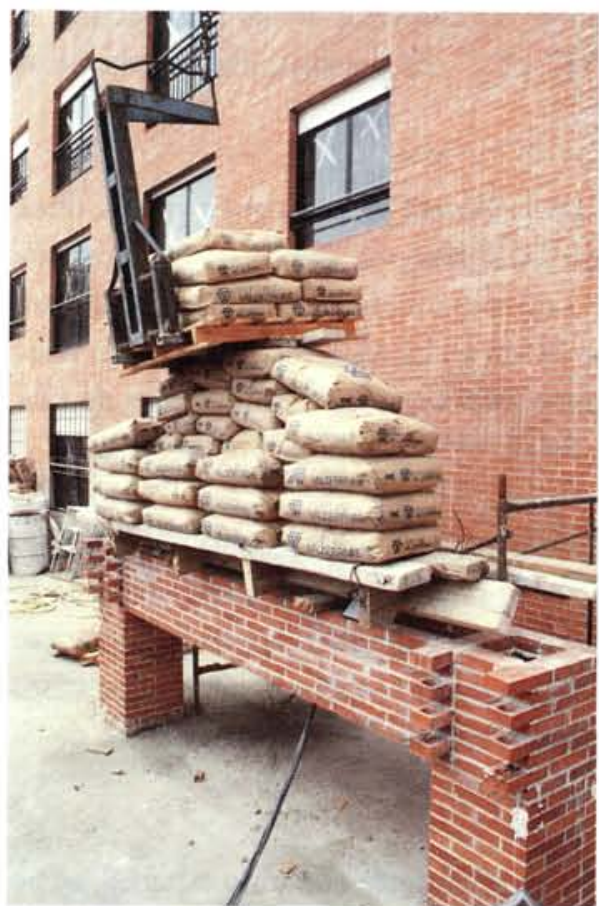

Fig. 3b.-Prueba de carga en obra de los dinteles dobles.

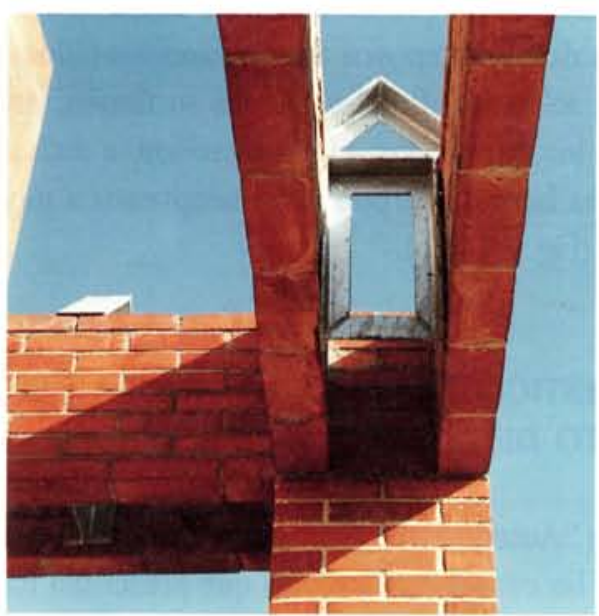

Fig. 4b.-Apoyos metálicos a la espera de soportar la cubierta prefabricada del tetrapilono.

for de $30 \mathrm{~mm}$ en el primer tendel, seguido de una de $50 \mathrm{~mm}$ en el segundo. En el ensayo realizado a pie de obra se ha aumentado 7 veces la carga prevista, sin siquiera manifestarse signos de fisuración (Fig. 3 a y b).

La originalidad de estas cubiertas de fábrica reside en que son de planos rectos trabajando a flexión, que no generan empujes al no tener curvatura, y que están construidas de una sola rosca.

Las cubiertas llevan la investigación de la fábrica armada al campo de los prefabricados, habiéndose realizado en taller. 
Informes de la Construcción, Vol. 44 n. ${ }^{\circ} 421$, septiembre/octubre, 1992

La construcción de las cubiertas de los tetrapilonos, en dos versiones "l" y "2", da personalidad propia a cada una de ellas.

Externamente las cubiertas se distinguen por la dirección de sus hiladas, si bien en ambos casos el armado se ha dispuesto horizontalmente en anillos. En un caso, las armaduras se sitúan en los tendeles horizontales, mientras que en el otro atraviesan las perforaciones de marca del ladrillo Palau.

La versión " 1 ", constructivamente sencilla y lógica, contrasta con la "2" de gran dificultad. La ubicación de los solapes de las armaduras, conformación de esquinas, cortes de piezas, etc., son muy distintos en ambos casos. Se han utilizado armaduras Murfor inoxidables de 50 milímetros de ancho.

Posteriormente a su transporte conjunto especial, se posan sobre los tetrapilonos.

Para dar la sensación de que las cubiertas descansan en el aire, se han diseñado apoyos triangulares metálicos, que las elevan sobre los dinteles que las sostienen, dejando pasar la luz entre ellos. El contacto entre dichos elementos se ha hecho interponiendo neoprenos a modo de juntas. (Fig 4 a y b).

\section{"ACW": INVESTIGACIÓN PARA LA MEJORA DEL CERRAMIENTO DE FÁBRICA (4)}

El cerramiento "Autoportante Cavity Wall" (ACW) plantea solucionar las causas de patología que presentan los muros capuchinos, debido a las conexiones existentes entre ambas hojas de fábrica.

El ACW supone una apuesta por un cerramiento de calidad, donde se aprovechen mejor las cualidades de los materiales de fábrica, se evite la fisuración, se perfeccione el comportamiento térmico y se solventen los problemas de humedad.

El espíritu del $\mathrm{ACW}$ consiste en construir y mantener separadas ambas hojas del "cavity wall", sin llaves de atado entre ellas. Ello permite que tengan un comportamiento estático independiente, solucionando por separado la actuación de cada una de ellas, sin implicarse entre sí, aunque cumplan un funcionamiento conjunto como cerramiento.
Es posible independizar ambas hojas, en amplios paños de fábrica, si se hace la hoja exterior autoportante pasando por delante de los forjados, y se construye con fábrica armada, considerándola como un material compuesto con las cualidades " $\mathrm{ABC}$ " expuestas.

El cerramiento armado " $\mathrm{ACW}$ ", se construye en "cuatro etapas", "de dentro a fuera" y "de abajo a arriba", considerando una edificación de estructura reticular. Para facilitar la exposición se ha utilizado como "cerramiento tipo" el del bloque de viviendas en "El Espinillo", del mismo autor (Fig. 5).

\section{Etapa: Levantamiento de la estructura}

Se levanta la estructura colocando los perfiles que permitirán anclar la fijación de la hoja exterior (1A).

Los soportes y forjados de la estructura mantendrán el mismo haz exterior, o frente (1B).

Habrá que proveer el tipo de apoyo para el arranque de la hoja exterior (4A).

2. Etapa: Ejecución de la hoja interior del cerramiento Se levanta la hoja interior del ACW a haces de estructura (1B). En prevención de fisuración, por exceso de flecha del forjado, se armarán las primeras hiladas del tabique. Se apoyará la hoja sobre una lámina de separación, y dispondrá una junta comprensible e ignífuga en su parte superior junto al forjado (2A).

Se organizará el espacio para la caja de persiana (2B).

\section{3.' Etapa: Aplicación del aislamiento}

Construida la hoja interior, se colocará el aislamiento proyectado o en planchas, evitando los puentes térmicos. El ACW permite garantizar la eficacia del aislamiento, al disponerse adherido exteriormente a la hoja interna, en continuidad sobre elementos estructurales, tabiquería, caja de persianas, etc. (3A).

Es necesario colocar algún tipo de barrera ignífuga, a nivel de forjado, que evite la propagación del fuego por la cámara (3B).

\section{4. ${ }^{\text {a }}$ Etapa: Construcción de la hoja exterior de}

fábrica armada

Se levanta la hoja exterior posteriormente a la colocación del aislamiento, dejando la separación prevista para la cámara de aire, ventilada al exterior a través de llagas sin rellenar. 


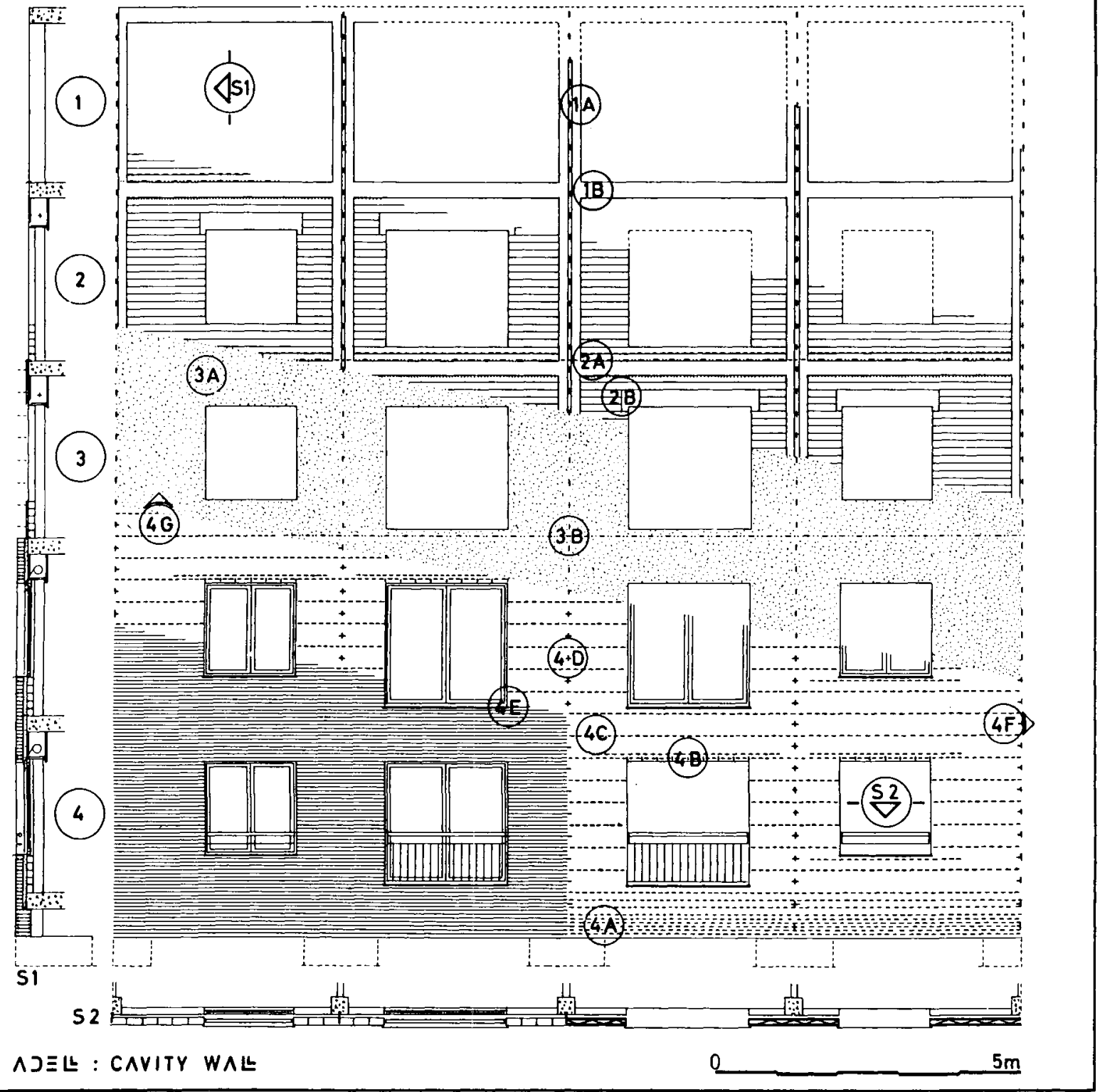

Fig. 5.- "Autoportante Cavity wall":

Proceso de construcción del "ACW" con hoja exterior autoportante de fábrica armada.

\section{1 a ETAPA: LEVANTAMIENTO DE LA ESTRUCTURA}

1.A-Perfil para los anclajes de la hoja exterior. 1.B-Soportes y forjados al mismo frente.

\section{ETAPA: EJECUCIÓN DE LA HOJA INTERIOR DEL CERRAMIENTO}

2.A-Armado inferior y regular de la hoja interior. 2.B-Caja de persianas a haces de tabiquería.
3. ETAPA: APLICACIÓN DEL AISLAMIENTO

3.A-Aislamiento aplicado en continuidad.

3.B-Barrera ignifuga a nivel de forjado.

4. ETAPA: CONSTRUCCIÓN DE LA HOJA EXTERIOR DE FÁBRICA ARMADA

4.A-Arranque en apoyo discontínuo del muro autoportante. 4.B - Armado de dinteles de fábrica armada.

4.C-Armado regular de la hoja exterior de fábrica armada. 4.D-Anclaje de la hoja exterior a los perfiles $1 \mathrm{~A}$.

4.E -Relación entre carpintería, vierteaguas, guía persiana. 4.F - Juntas de dilatación o cambios de plano.

4.G-Remate superior en peto de cubierta o junto a forjado. 


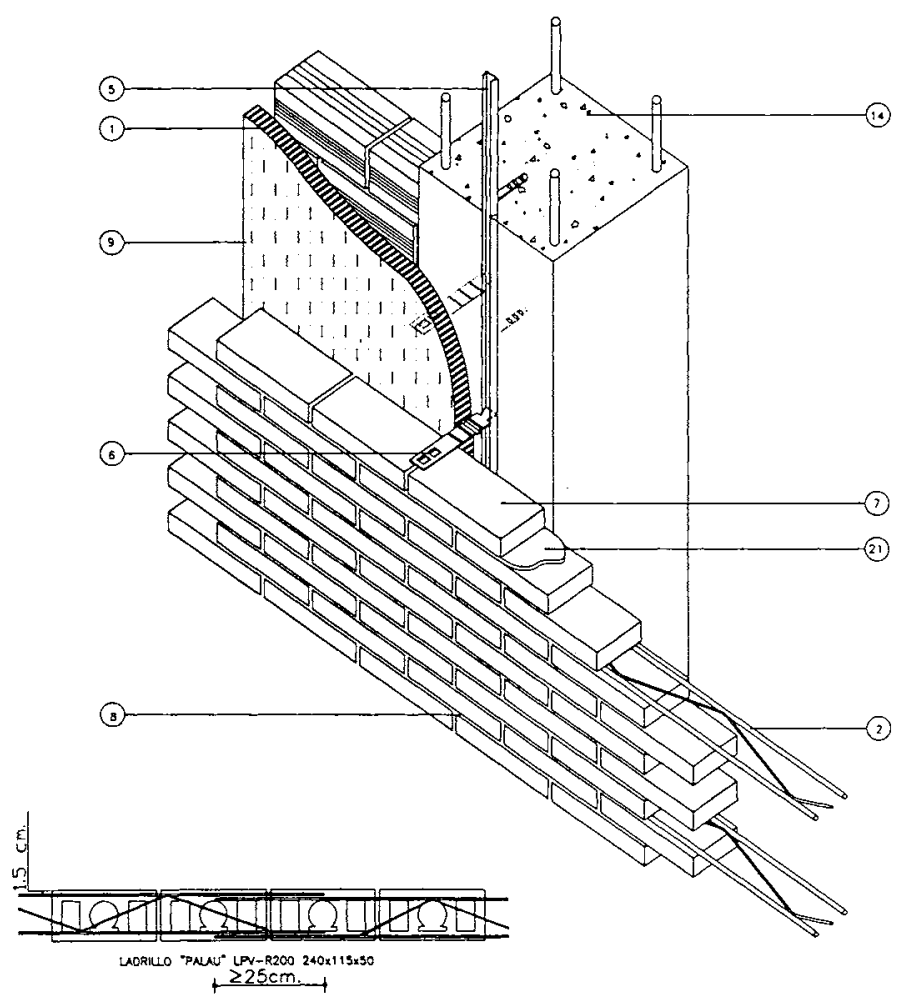

\section{a}

1.-Tabicón ladrillo hueco doble.

2.-Armadura "Murfor" RND.5/E-80.

5.-Perfil de anclaje "Halfeneisen" tipo HMS 25/15-D.

6.-Anclaje "Halfeneisen" tipo ML 120/3 cada seis hiladas de altura.

7.-Ladrillo "Palau" LPV-R200 $240 \times 115 \times 50$.

8.-Muro cara vista $1 / 2$ pie.

9.-Aislamiento proyectado de $40 \mathrm{~mm}$.

14.--Soporte de hormigón armado.

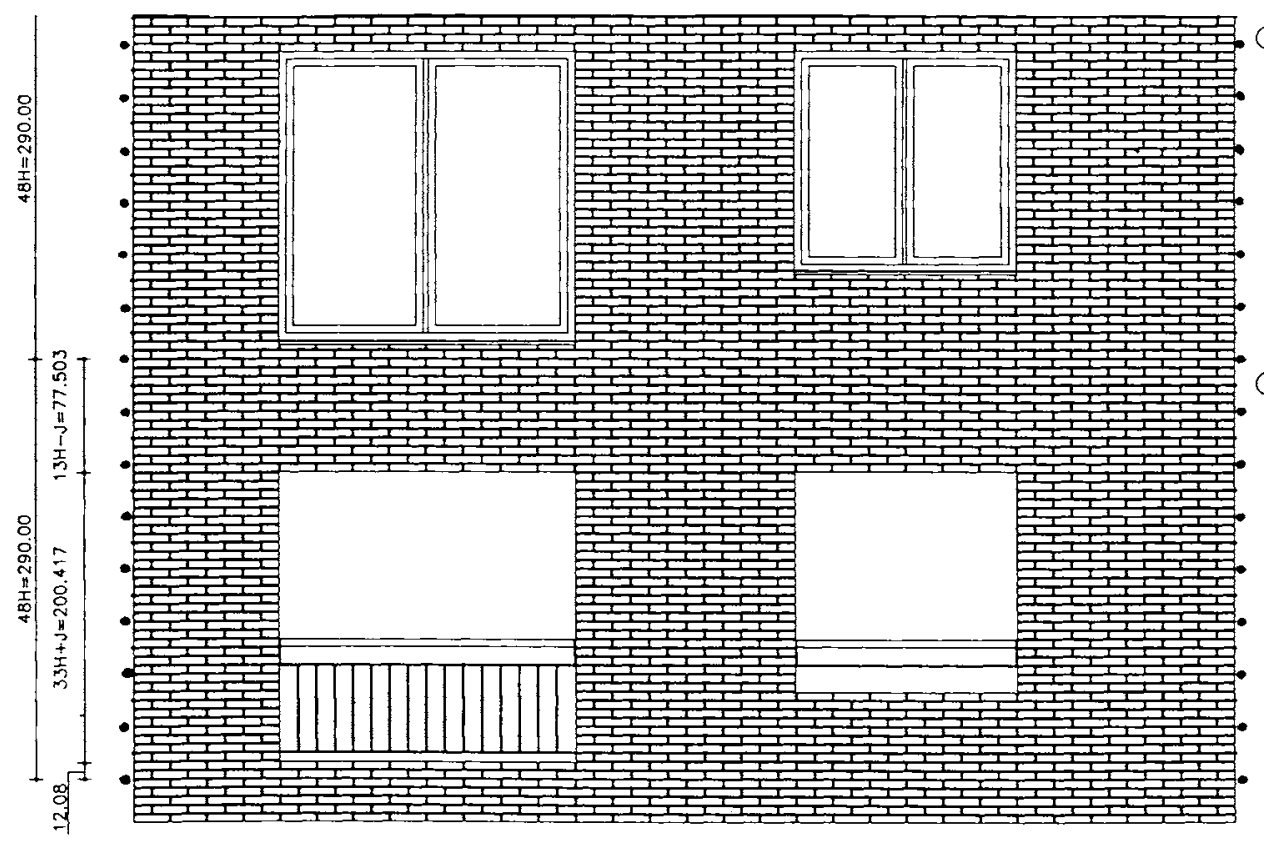

b
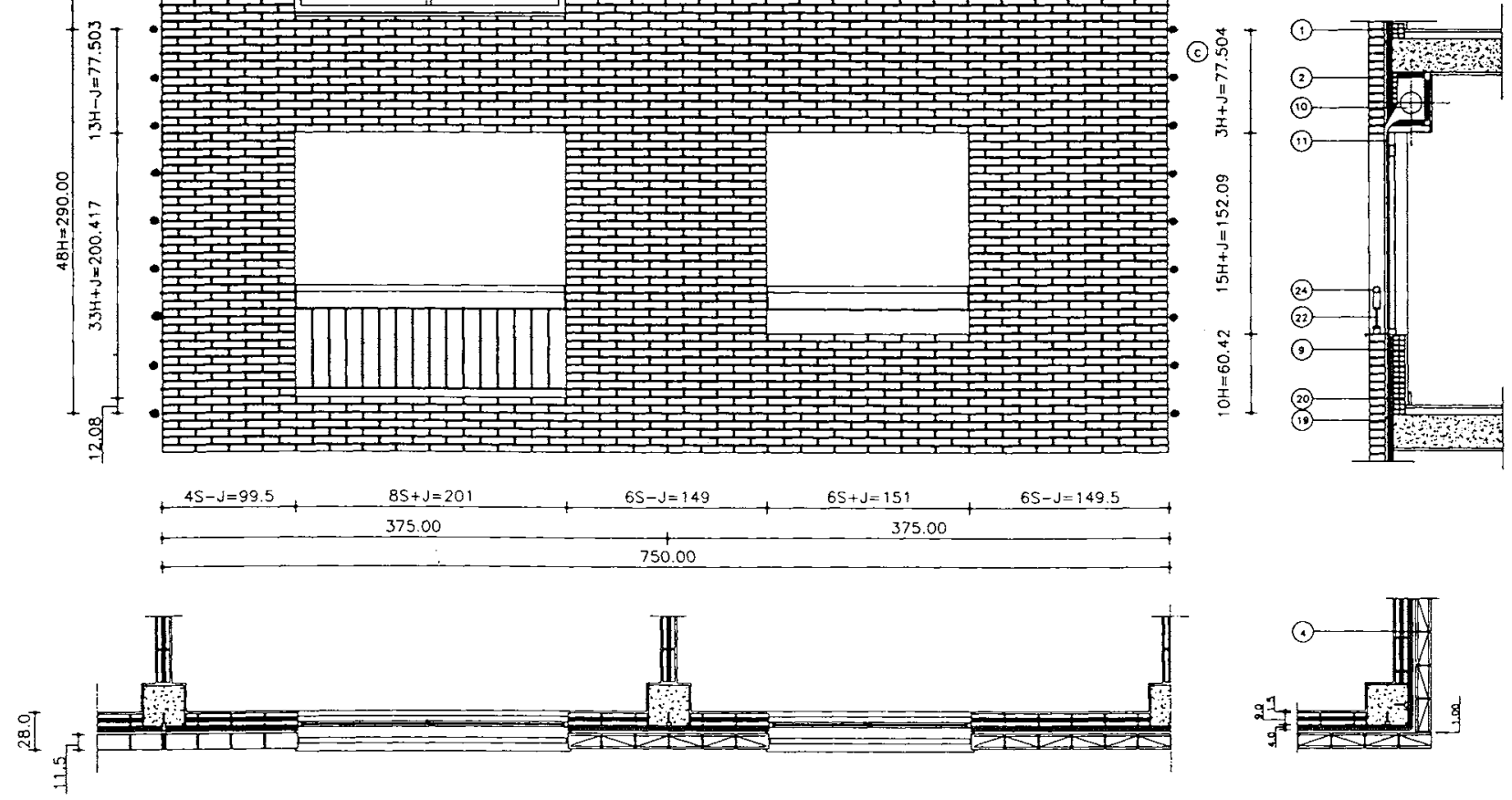

Fig. 6 a y b.-Alzado y detalles del "ACW" planteado para el cerramiento del edificio de "El Espinillo". 
El "Aumento de separación de juntas de dilatación (A)" es notable si se disponen armaduras regularmente distribuidas en los tendeles, a razón del $0,05 \%$ de la sección de la fábrica. Esto supone armar cada $30-50 \mathrm{~cm}$ de altura (4F). Hay que independizar con juntas el encuentro de las fábricas de planos distintos.

Si se considera la capacidad de trabajo a "Flexión vertical (B)" que tiene la fábrica armada, es posible apoyar puntualmente el arranque de la hoja exterior del cerramiento, caso de no disponerse de una base de apoyo continuo. El armado correspondiente, según cálculo, podrá ajustarse de acuerdo al ancho de la fábrica y al número de tendeles existentes (4A).

Habrá que disponer una barrera impermeable próxima al arranque, capaz de recoger, canalizar y expulsar al exterior las aguas que pudieran infiltrarse y descender por la cámara de aire desde plantas superiores. La barrera evitará también que las aguas asciendan por la fábrica, desde el suelo, por capilaridad.

Esta misma capacidad de trabajo a "Flexión vertical (B)", permite también salvar el vacío de los vanos de fábrica. En los dinteles de los huecos podrá dejarse visto inferiormente el material de fábrica. Las piezas se sujetan mediante ganchos engarzados en la armadura de la hilada superior, que se introducen en las llagas (4B).

La fábrica regularmente armada por tendeles, con armaduras prefabricadas, tienen capacidad de trabajo a "Flexión horizontal (C)" entre apoyos verticales convenientemente distanciados. Esta cualidad se aprovecha en el ACW para evitar tener que atar ambas hojas entre si (4C).

Si se arman los tendeles de la fábrica cada $40-50 \mathrm{~cm}$ de altura, se pueden salvar luces normales (de 4 a $6 \mathrm{~m}$ ) con fábricas de gruesos habituales (en España los anchos de los ladrillos comunes son 115 ó $140 \mathrm{~mm}$ ), frente a una acción de viento de valor intermedio.

Al levantar la fábrica se irán colocando las llaves (4D) sobre el perfil (1A). Se utilizará el anclaje apropiado, que asegure las libertades de movimiento de la hoja exterior, horizontal y verticalmente dentro del plano de fachada, en función de las dimensiones del paño de fábrica armada entre juntas (4F) (Fig. 6 a y b).
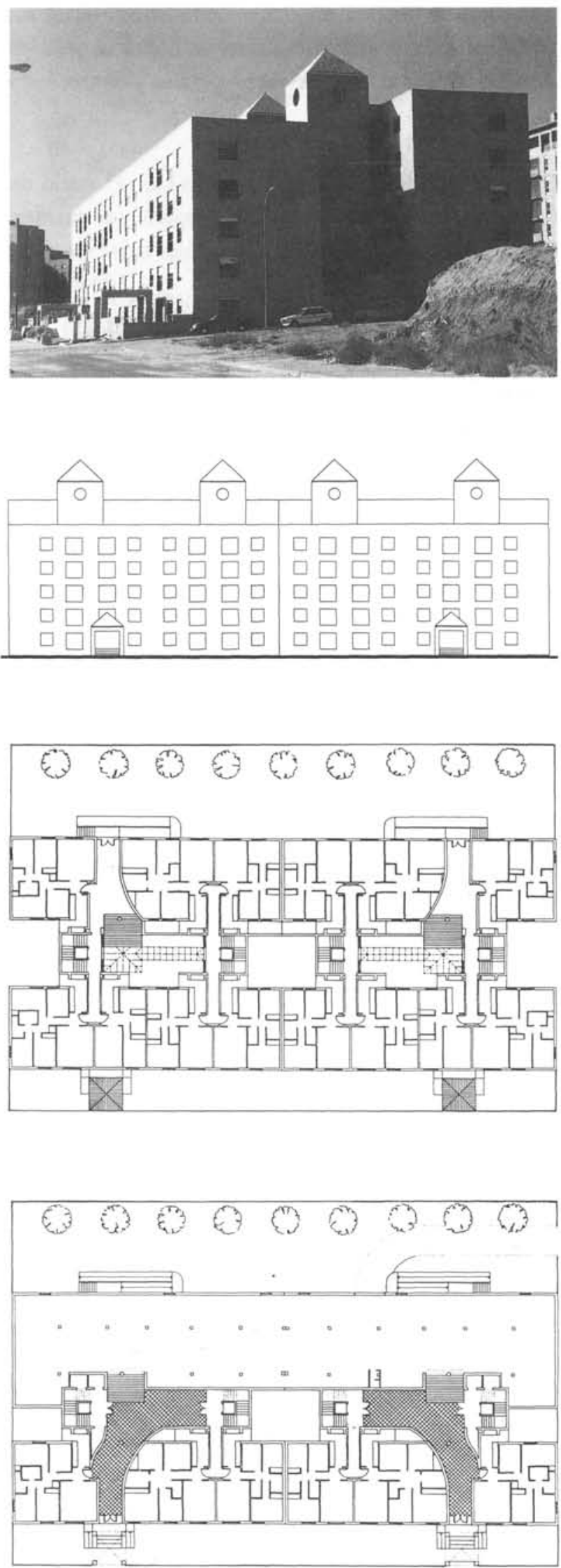

Fig. 7.-Vista, alzado y plantas del edificio de "El Espinillo". 
Para aplicar el ACW en alturas superiores a 3 ó 4 plantas, es necesario hacer cálculos precisos, ya que los movimientos de dilatación vertical de la hoja exterior son apreciables. Este movimiento puede limitarse repitiendo el ACW por tramos de varias plantas pasantes entre forjados de apoyo.

En el remate del peto de cubierta, o bajo el vuelo del forjado de arranque de otro muro superior, se mantendrá también la independencia de ambas hojas en su coronación $(4 \mathrm{G})$.

El buen funcionamiento del ACW sólo es posible cuidando el diseño de aquellos elementos que relacionan ambas hojas, con el fin de garantizar el libre movimiento entre ellas.

La carpintería se recibirá solamente sobre la hoja interior, al igual que la guía de la persiana que se ubicará en el hueco de la cámara de aire.

El vierteaguas sujeto a una de las hojas recogerá y alejará la lluvia mediante solapes y goterones (4E).

Pretender mejorar el cerramiento, no nos ha de impedir ver que el ACW tiene también sus dificultades, entre ellas están:

- contar con que la hoja interior ha de soportar la acción del viento durante la construcción,

- cuidar la ejecución de la hoja exterior de fábrica armada con sus anclajes.

\section{EDIFICIO DE VIVIENDAS EN “EL ESPINILLO"}

Edificio de 76 Viviendas VPO en "El Espinillo", Villaverde, Madrid. EMV-Ibercesa 1989-1992. Arquitectos-JM AdellD. de la Piedra. (Fig. 7).

La fábrica armada constituye el cerramiento de "El Espinillo" en toda su amplitud. La modulación, los huecos, las juntas, etc., son partícipes de las ventajas del armado, evitando la fisuración de la fábrica en el tiempo.

Sin embargo, el cerramiento que envuelve la estructura de hormigón supone una variante sobre el planteamiento del "ACW", por cuanto la hoja exterior también apoya en los forjados.

La composición de fachada combina huecos cuadrados de dos tamaños: Los de $2 \mathrm{~m}$ para el estar-comedor y los de 1,5 m para dormitorios. La luz mayor de hueco aprovecha la longitud de la armadura prefabricada de $3 \mathrm{~m}$, contando con sus $50 \mathrm{~cm}$ de anclaje a cada lado, para organizar el dintel sin requerir solapes. (Fig. 9 a y b).

Los dinteles de los huecos muestran la tabla de las piezas de ladrillo macizo a soga, evitando el puente térmico que generan los cargaderos habituales de otros materiales.

Toda la fábrica exterior, de medio pie de grueso, está armada cada 6 hiladas de altura, siguiendo la modulación vertical de fachada en ocho grupos de 6 hiladas por planta. (Fig. 8 a y b).

En la disposición de los huecos, se ha hecho coincidir el correspondiente tendel armado de la modulación a la altura del dintel, cumpliendo así la armadura la triple función " $\mathrm{ABC}$ ".

Gracias a estar los tendeles armados cada $36 \mathrm{~cm}$ de altura, las juntas de la fábrica cerámica se han podido distanciar hasta coincidir con las de la estructura de hormigón cada 33 metros.

En los petos de cubierta, las armaduras han permitido unir las dos hojas de fábrica de piezas distintas, realizadas en diferentes fases de obra, permaneciendo en espera entre ambas.

El edificio está situado en un barrio de nueva ordenación, donde destaca por su sencilla volumetría y composición. De lejos se reconoce por sus cuatro torreones que, de cerca, recuerdan sus dos tetrapilonos.

Se trata de dos bloques escalonados paralelos a fachada, de 5 plantas de altura, con patios centrales entre torreones de escaleras rematados con cubiertas de ladrillo a cuatro aguas.

El acceso se hace bajo el tetrapilono situado en el jardín delantero, y da paso a un portal que sorprende por sus paredes onduladas.

El portal relaciona la zona común entre el jardín de acceso, y el posterior con una escalinata de juegos que salva el desnivel de la calle, situada bajo una pérgola a cuatro aguas.

http://informesdelaconstruccion.revistas.csic.es 
El programa de viviendas se resuelve con sólo 4 tipos distintos de 2, 3 y 4 dormitorios.

Las fábricas inclinadas de las cubiertas de ladrillo resaltan sobre las planas fachadas de sobria composición.

Los tetrapilonos, con su desnudez estructural, dan idea de que la fábrica armada preside la construcción del edificio.

Fig. 8.-Construcción de dinteles con fábrica armada:

a) Hueco $2 \mathrm{~m}$ en fábrica de $1 / 2$ ' mostrando la tabla de los ladrillos macizos PALAU.

b) Hueco de 2,50 $\mathrm{m}$ en fábrica de $l$.

Colocación de los ganchos para dinteles en las llagas de las piezas de la primera hilada, engarzados en las armaduras Murfor dispuestas sobre el tendel.

a

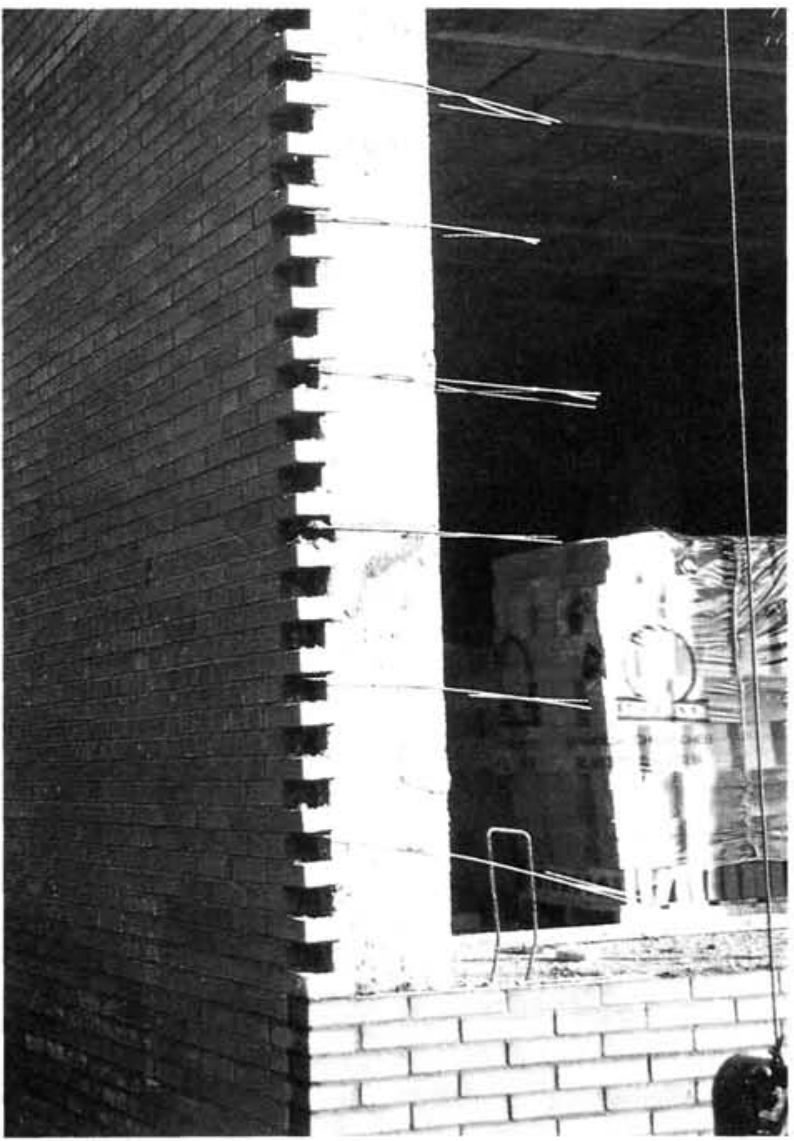

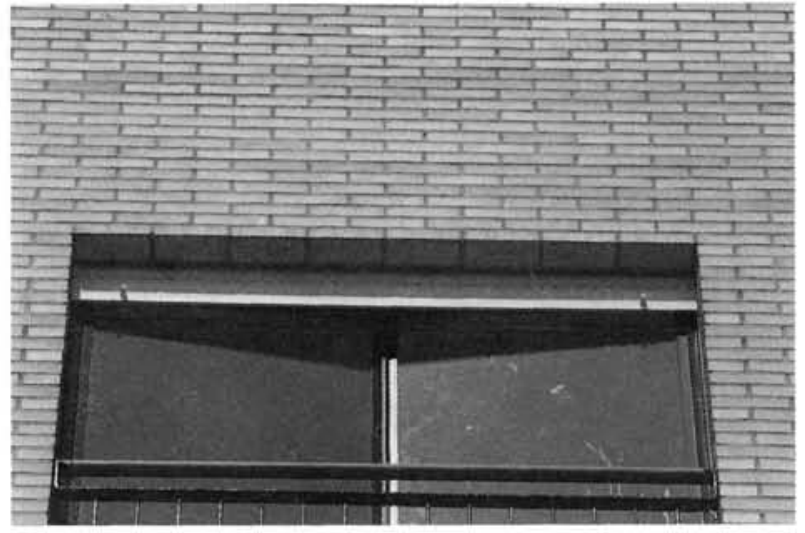

a

b

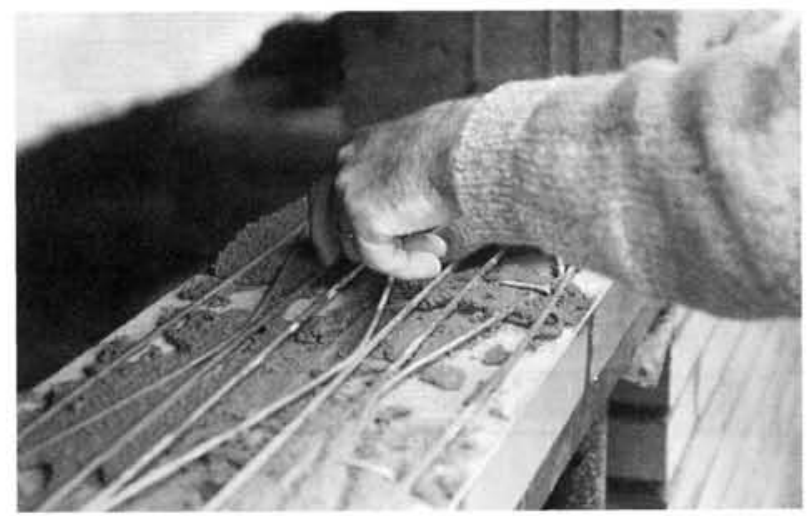

b

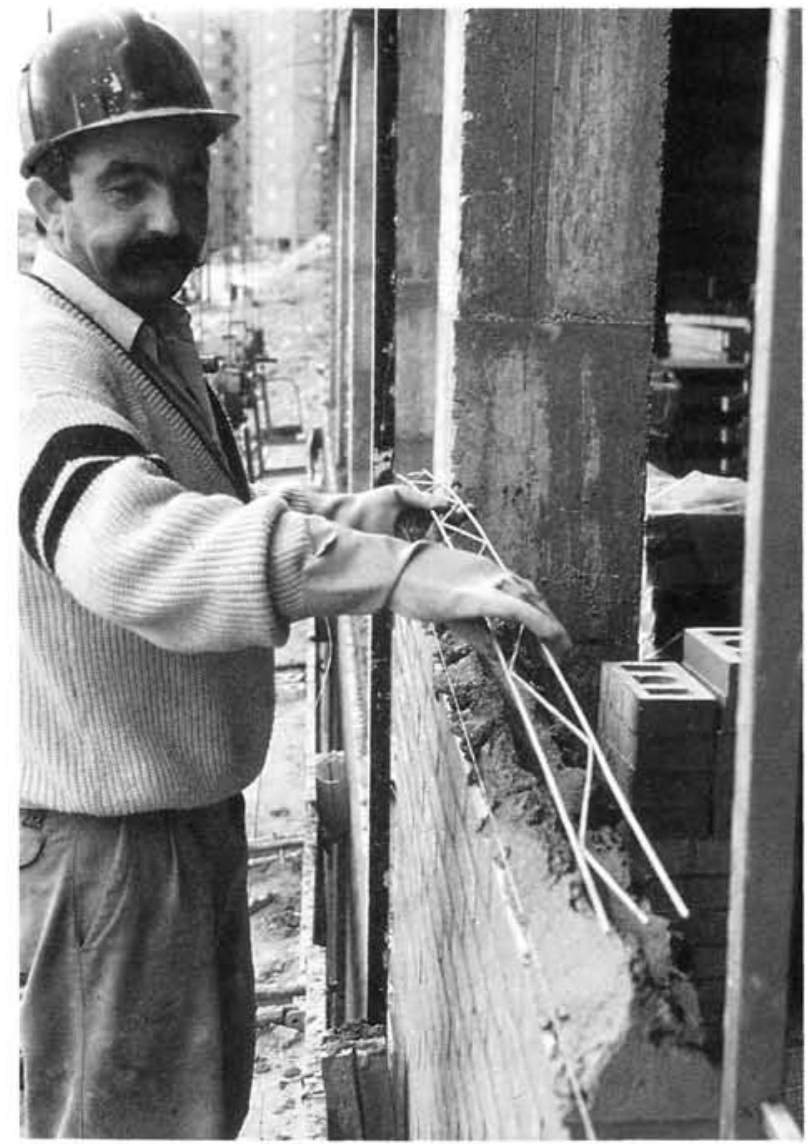

Fig. 9.-Construcción del cerramiento de "El Espinillo". a) Hoja exterior con armaduras cada 6 hiladas de altura. b) Colocación de la armadura Murfor en un tendel. 

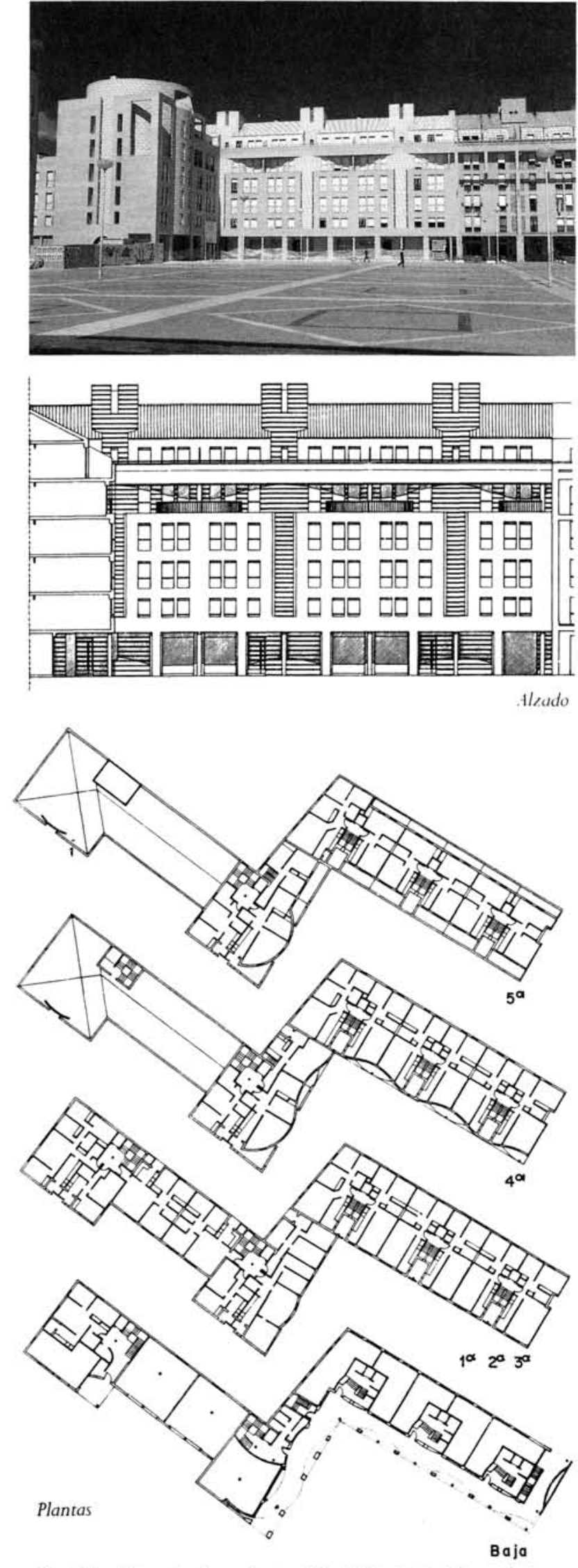

Fig. 10.-Vista, alzado y plantas del edificio de la "Plaza de la Remonta".

(c) Consejo Superior de Investigaciones Científicas Licencia Creative Commons 3.0 España (by-nc)

\section{EDIFICIO DE VIVIENDAS EN LA PLAZA DE LA REMONTA}

Edificio de 57 viviendas VPO. Plaza de la Remonta, Tetuán, Madrid. EMV-Corviam 1988-1991, Arquitectos-JM Adell y Colaboradores. (Fig. 10).

La fábrica armada se ha utilizado también en este edificio, de forma incipiente, pero significativa.

En la esquina entre la plaza y la calle Maestros Ladrilleros, se levanta un torreón cilíndrico, que remata el edificio con una terraza abierta sobre la ciudad.

La fábrica armada soluciona con sencillez, homogeneidad y economía, las esbeltas alas que flanquean el torreón circular.

La combinación de armaduras de distintos anchos permite cumplir diversos objetivos a esta fábrica armada (Fig. 11).

El dintel tiene $3 \mathrm{~m}$ de luz, $72 \mathrm{~cm}$ de canto y $24 \mathrm{~cm}$ de espesor. Sus proporciones afinan el discurso técnicoformal de la fábrica armada, como indican las coincidencias del cálculo.

El cálculo requiere sólo dos armaduras Murfor localizadas en los primeros tendeles para soportarse. Además, esta cuantía de armado coincide, dadas las proporciones del dintel, con el armado mínimo del $0,05 \%$ de la sección, que tiene que tener para considerarse fábrica armada.

Por razones constructivas, se han empleado más armaduras que las requeridas en la cuantía de armado mínimo, distribuidas en hiladas superiores, para atar las dos hojas a soga del muro doblado, visto a dos frentes.

Analicemos el edificio desde la óptica de la fábrica armada (Fig. 12):

- Con las consideraciones expuestas en "ACW", se puede observar el edificio de la Remonta, enfocándolo como si se fuera a construir el cerramiento de hoja exterior autoportante de fábrica armada. 

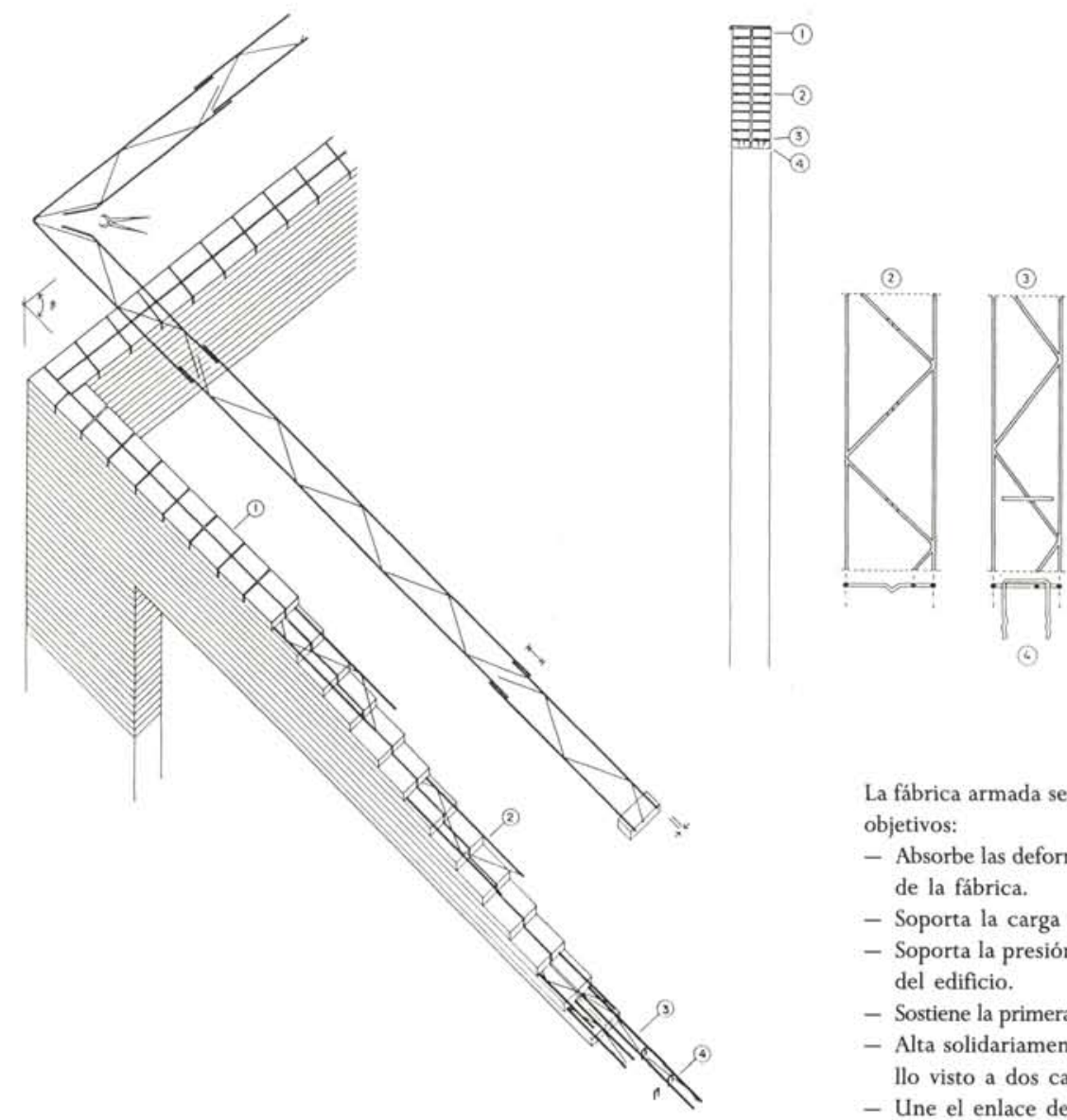

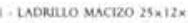

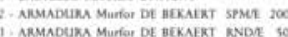
4. ARMADLIRS Murfar DE HEKALKT UHK/DOA/44

La fábrica armada según el dibujo, cumple los siguientes objetivos:

- Absorbe las deformaciones de dilatación o contracción de la fábrica.

- Soporta la carga del dintel.

- Soporta la presión o succión del viento sobre las alas del edificio.

- Sostiene la primera hilada de ladrillos macizos del dintel.

- Alta solidariamente las dos hojas de fábrica de ladrillo visto a dos caras.

- Une el enlace de esquina en ángulo $<90^{\circ}$.

Fig. 11.-Alas del Edificio de viviendas de la "Plaza de la Remonta".

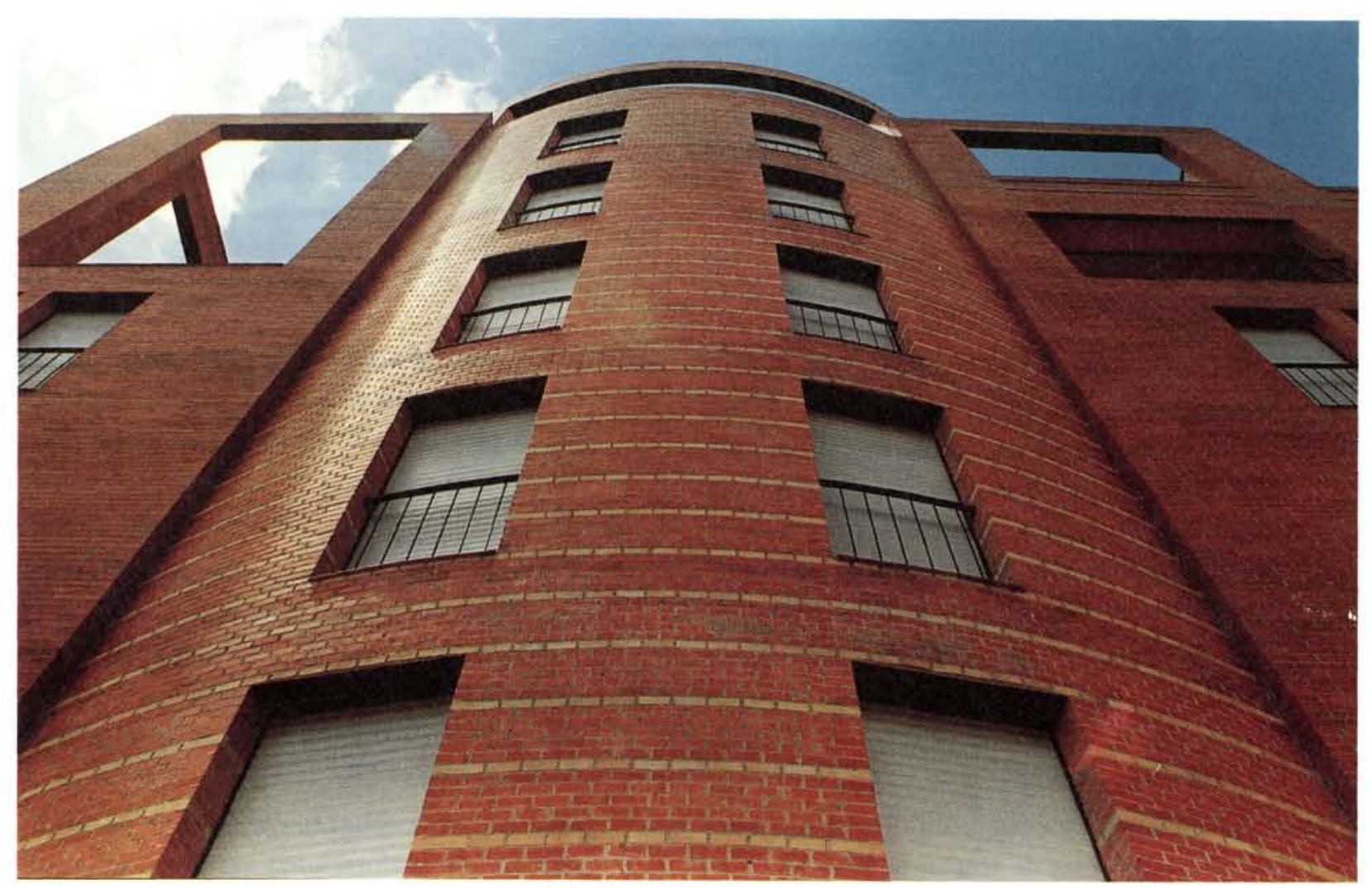

Fig. 12.-Alas junto al torreón cilíndrico de la Plaza de la Remonta. 

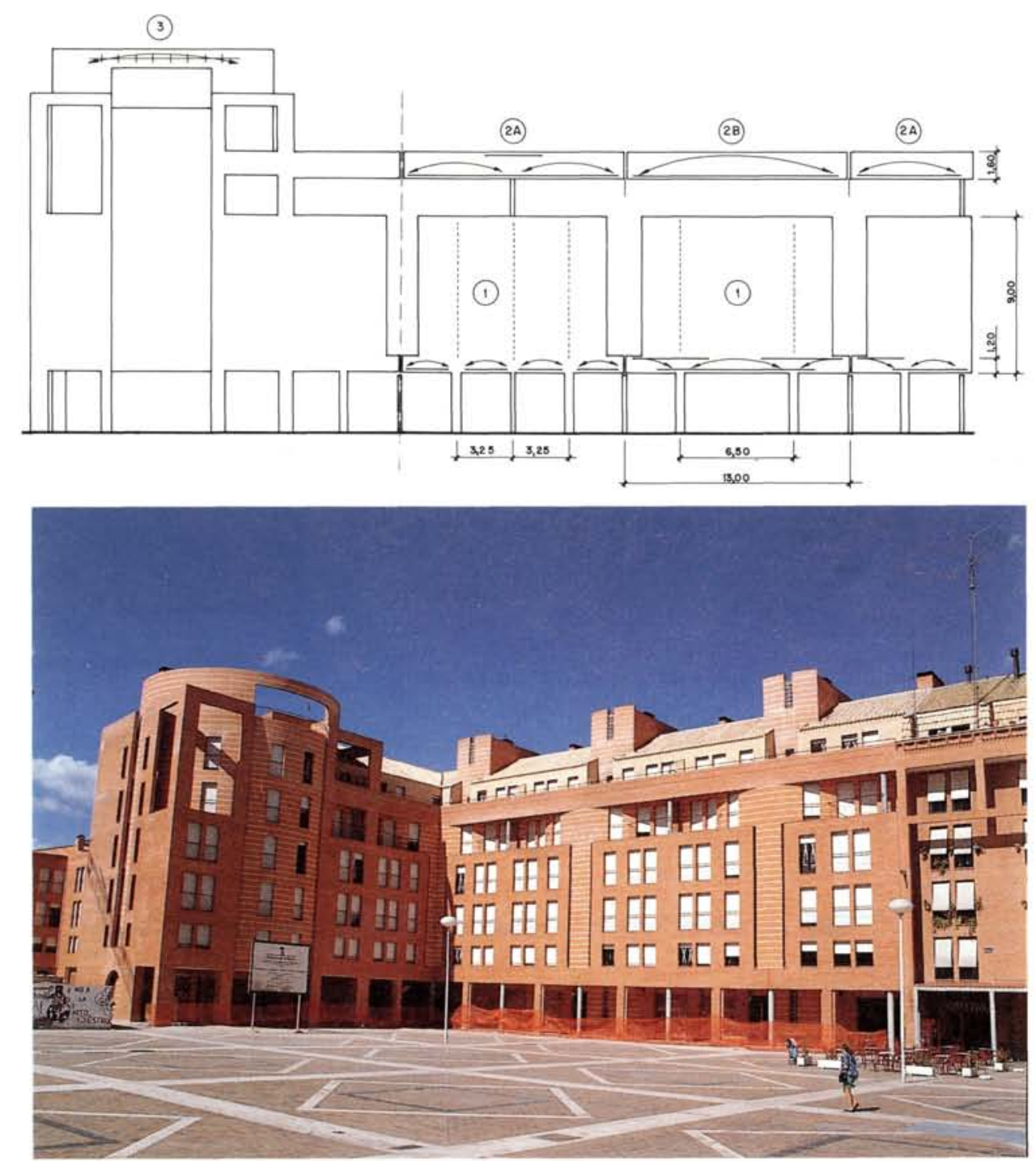

Fig. 13.-Análisis de las posibilidades de la fábrica armada considerando el cerramiento del edificio de la "Plaza de la Remonta".

- Cogiendo el esquema del alzado (Fig. 13):

$1^{\circ}$.) Se podría plantear un cerramiento "ACW" de tres plantas de altura, arrancando sobre el soportal, con apoyos en los pilares distanciados a $3,25 \mathrm{~m}$ o bien a $6,50 \mathrm{~m}$. En ambos casos, para salvar la luz sería suficiente armar las cuatro primeras hiladas del peto inferior, de 1,2 $\mathrm{m}$ de altura.

2. A) Se podría plantear perfectamente en el peto de cornisa, de 1,6 m de canto, un dintel corrido de fábrica armada con apoyos cada $6,5 \mathrm{~m}$, armando las primeras hiladas.

2. B) Tambien cabría la posibilidad de ir a una gran luz de 13,0 m, caso de aceptar la fisuración. Cosa no aconsejable en este caso al tratarse de fá- brica vista y al exterior, aunque pudiera hacerse con armaduras inoxidables. El Manual Murfor español, plantea poder aceptar la de fisuración en dinteles (2).

Igualmente, considerando la zona del torreón circular:

3.') Cabría la posibilidad de solucionar el dintel curvo con fábrica armada, utilizando armaduras tridimensionales Murfor RE. Esta armadura, permite armar bidireccionalmente con anillos superpuestos, que son capaces de soportar torsiones debido a sus cercos (3).

Para ello sería obligado disponer de un ladrillo que tuviera perforaciones verticales suficientemente amplias, y una buena dosis de paciencia. 
Informes de la Construcción, Vol. 44 n. ${ }^{\circ} 421$, septiembre/octubre, 1992

La Plaza peatonal de la Remonta es una actuación arquitectónica nueva, dentro del antiguo barrio de Tetuán, conocido por sus buenos ejemplos de Arquitectura de Ladrillos del siglo XIX.

La complejidad volumétrica y el ziz-zageado del solar han obligado a definir 23 tipos de viviendas distintas de entre las 57 construidas, para dar unidad de composición a la plaza, en continuidad con las obras existentes y resolver el programa.

El edificio de la Plaza de la Remonta, asume un doble compromiso:

- corresponder con la historia del barrio, con sus fábricas de ladrillo a tizón y sus huecos verticales;

- hacer la actuación acorde con la modernidad, con fábricas de ladrillo a soga de amplios huecos horizontales.
Su construcción supone una apuesta por el futuro, con la renovación de las fábricas mediante la fábrica armada.

El edificio, con sus fábricas curvas y onduladas de bandas a color, constituye un telón urbano que envuelve el espacio público, abriéndose en un ventanal sobre el cielo de Madrid. (Fig. 14).

\section{BIBLIOGRAFÍA}

(1) Josep M.a Adell. Razón y Ser de la Fábrica Armada. Informes de la Construcción n. ${ }^{\circ} 421$, Instituto Eduardo Torroja. Madrid. Consejo S. Invest. Científ. Septiembre-octubre 1992.

(2) Adell/Lahuerta. La fábrica armada. Manual Murfor de Bekaert. Bekaert Ibérica, S. A. Barcelona 1992.

(3) Luiz Oliveira. La armadura tridimensional para la fábrica armada. Informes de la Construcción n. ${ }^{\circ} 421$, Instituto Eduardo Torroja. Madrid. Consejo S. Invest. Cientif. Septiembre-octubre 1992.

(4) Josep M.a Adell. The Architectural Potential of Bedjoint Reinforced Masonry. Proceedings of the $3^{\text {rd }}$ International Masonry Conference, London $26 \cdot 28$ octubre 1992.

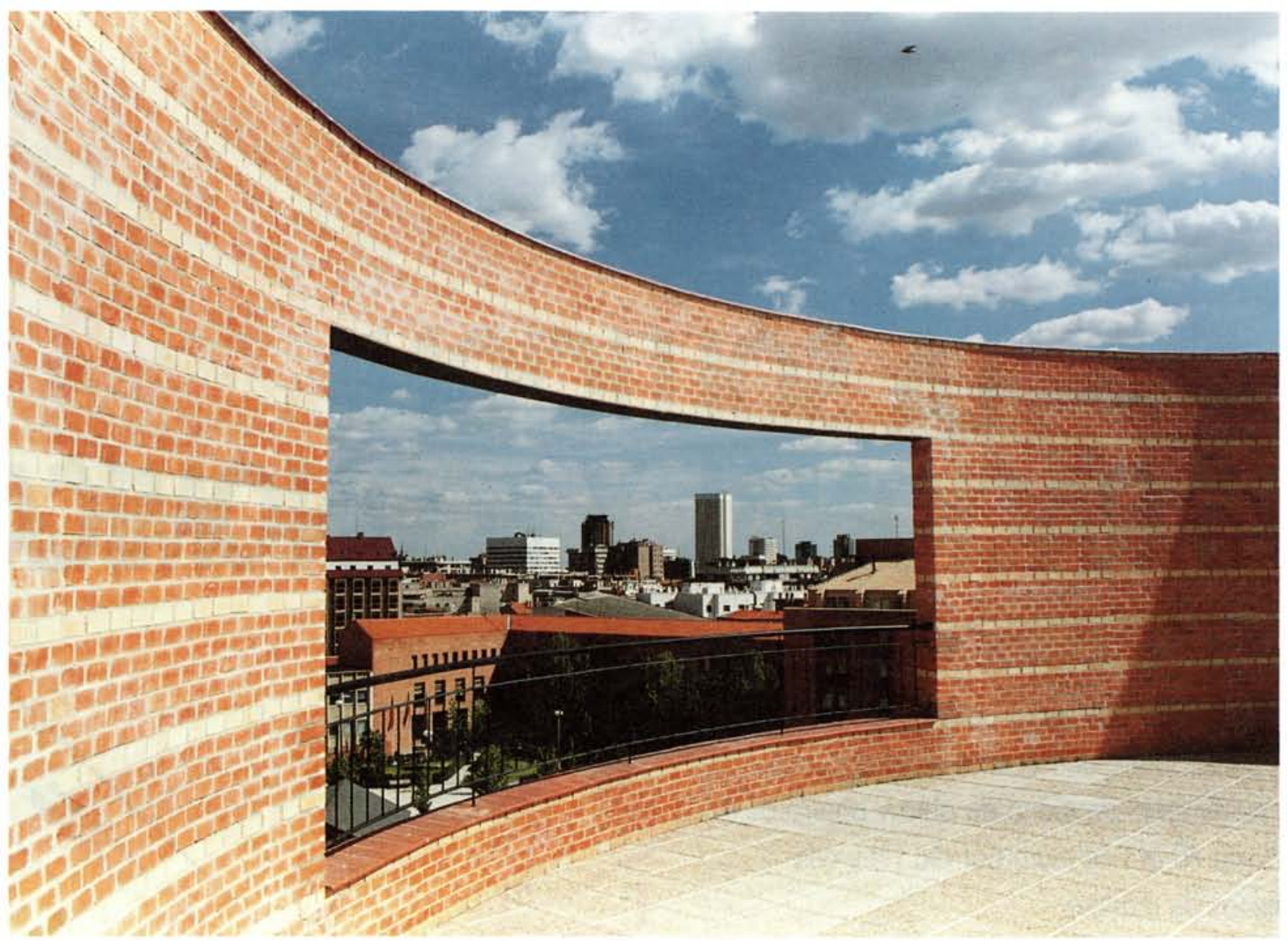

Fig. 14. - El cielo de Madrid enmarcado en fábrica curva de ladrillos a color. Vista desde la terraza de la Plaza de la Remonta. 